\title{
Study on Value Portfolio from the Perspective of COVID-19: A Case Study of Aviation, E-commerce and Retail Industry
}

\author{
Xinyue Guo ${ }^{1, a, *, \dagger}$, Yixuan $\operatorname{Liu}^{2, b, *, \dagger}$, Zheheng $\operatorname{Liu}^{3, c, ~}{ }^{*}, \dagger$ \\ ${ }^{1}$ Department of Mathematical Sciences, Xi'an Jiaotong-Liverpool University, Shanghai, China \\ ${ }^{2}$ School of Science, East China University of Science and Technology, Shanghai, China \\ ${ }^{3}$ School of Arts and Science, University of Washington, Seattle, United States \\ ${ }^{*}$ Corresponding author.Email: ${ }^{a}$ Xinyue.GUO19@student.xjtlu.edu.cn, ${ }^{b} 19002285 @$ mail.ecust.edu.cn,
}

cliuz719@uw.edu

\begin{abstract}
Diversified portfolio is a classic investment strategy which was put forward in the 1950s. However, due to the outbreak of COVID-19 in 2019, the traditional portfolio theory cannot be completely directly applied to the investment. Based on the literature review, this paper sorts out the modern portfolio theory and analyzes three industries of Airline industry, retail industry, and e-commerce industry and the typical companies in these three industries: Delta Airline, Walmart and Amazon. On the one hand, the impact of COVID-19 on the development trend of various industries is analyzed through qualitative methods. The research results show that as the passenger volume of the aviation industry decreasing sharply in 2020 and 2021, it will suffer huge economic losses. For the traditional retail industry, as more people choose e-commerce as well, it will also suffer no small blow; E-commerce, meanwhile, is more likely to survive the recovery. Walmart shares were hit hard by the outbreak, Amazon shares rose sharply because of demand for online shopping, and Delta Airlines shares fell because the city shut down. On the other hand, a quantitative analysis method is applied to generate the correlation matrix of the three companies. A conclusion is drawn that consumer should increase the weight of Walmart in the three stocks, reduce the proportion of Amazon, and reduce the purchase of Amazon Delta Airline. The conclusions of this paper provide practical support and reference for investors' investment.
\end{abstract}

Keywords: COVID-19, Aviation industry, retail industry, e-commerce (case study), quantitative analysis, Qualitative analysis.

\section{INTRODUCTION}

Since the fourth quarter of 2019 , due to the outbreak and continuous spread of COVID-19, the global economy has been hit hard, economic growth has slowed down, and import and export trade pressure has continued to increase. According to the domestic economic data in the first quarter of 2020 released by the National Bureau of Statistics, the country's GDP showed negative growth. The international market is no exception. On the one hand, the epidemic has accelerated its spread worldwide, leading to a sharp rise in uncertainty and a setback in investor confidence, which has triggered turmoil in the financial and capital markets. On the other hand, to control the spread of the epidemic, countries have strictly restricted the movement of people and transportation, putting pressure on economic operations from both the consumption and production sides. Despite the huge impact on many industries, new types of consumption, such as online services, online education, and cloud office, are emerging. With the increasing inflationary pressure, the pressure of maintaining and increasing the value of the assets owned by investors is increasing, and investors begin to shift their attention from the investment of single financial products to the investment of diversified portfolios.

Domestic and foreign scholars have studied diversified portfolios for several decades. Study abroad since the fifties last century: Markowitz in 1952 paper 
"portfolio selection" and published in 1959, the diversification of portfolio choice: effective monograph in putting forward how to reduce the investment risk by diversification, marks the modern portfolio theory, at the same time, he put forward the mean-variance matrix investment model, and points out that to make the risk portfolio under the condition of the expected returns the minimum or maximum under the condition of given risk its benefit, must be the weight of portfolio of individual stocks [1]; In the construction of the portfolio model, Pastor proposed the Bayesian method in 2000: the problem of minimizing the residual estimation encountered in the portfolio components, to minimize the estimation error of the final result of the model. Compared with the traditional mean-variance model, this method can improve the stability of the model more [2]. In 2007, Raymond Kan and Guofu Zhou proposed a portfolio model that mixed the two optimal strategies, the "three-fund model", to improve the portfolio's efficiency on the whole [3]. In 2010, Anagnostopouios and Mamanis established a dynamic portfolio optimization model with three objectives and discrete variables, which found a balance between risks, returns, and the number of securities [4].

Domestic scholars began to study diversified portfolio investment at the beginning of this century. Based on the Markowitz mean-variance portfolio model, Wang Jian and Tu Xinshu proposed solving the portfolio's optimal weight by the geometric method in 2000. This method can solve the optimal weight of the portfolio under the condition of given return and given risk [5]. In 2005, Wang Xiuguo and Qiu Wanhua studied the portfolio problem based on the underlying risk control and constructed a dynamic portfolio model [6]. In 2006, Liu Mingming and Gao Yan constructed a mean-absolute dispersion portfolio model based on absolute deviation, which developed the mean-variance model [7]. In 2009, Chen Guohua, Chen Shou, Fang Yong, and Wang Shouyang simplified variance constraints through fuzzy constraints, proposed a fuzzy linear programming model for securities portfolios, and tested the feasibility of this model through concrete examples [8]. In 2008, Shi Yufeng and Zhang Shiying constructed a dynamic portfolio model based on timevarying correlation coefficients, which has certain practical and theoretical significance for controlling portfolio risks [9].

To sum up, we can find that the portfolio model is constantly developing and maturing, especially in the aspects of risk control, return fluctuation and the number of securities, and so on, and has achieved remarkable results. However, the outbreak of the new champions league the influence of different industry are different. So we are in the quantitative analysis for different securities portfolio, the history of the longterm data is often not too much reference. Qualitative analysis should also be combined with different industries under short-term epidemic situation is analyzed, and should not only pay attention to long-term application prospect in the industry. This article will adopt qualitative and quantitative analysis methods. In combination with portfolio model, aviation, retail, ecommerce industry three industry is analyzed, and the three kinds of typical Delta Airline company in the industry are Walmart and Amazon, using three companies as the research object. The establishment of portfolio diversification under the background of the new champions league epidemic model mining investment model, according to the results put forward the corresponding investment advice.

\section{DATA AND METHOD}

Styles can be applied using the style palette available within the template. To activate it the press Ctrl+Shift+s. Apply the style as required based on the content and context. (Please don't highlight your text in yellow.)

\subsection{Data}

In this paper, Delta Airline, Walmart, and Amazon were selected as the research objects, and the data from January 2020 to December 2020 were selected as the research samples. The optimal investment portfolio was analyzed through qualitative and quantitative analysis, respectively. The qualitative analysis mainly studies the stock prices, management policies, and corporate models of each company under the impact of COVID19 in 2020, while quantitative analysis finds out the best investment portfolio by changing the weight of three stocks.

\subsection{Method}

We first get the monthly stock price of three companies in 2020 and calculate the returns during that period. Then we calculate the average return of those returns and the standard deviation of those returns. We set average return matrix as matrix $\mathrm{R}$, and the standard deviation matrix as matrix SD.

Next, we calculate a matrix of DEMEAND returns divided by the square root of the number of returns minus 1 . Then we get the covariance matrix $S$ (1):

$$
\mathrm{S}_{\mathrm{N}}=\frac{1}{\mathrm{~T}-1}+\sum_{\mathrm{t}=1}^{\mathrm{T}}\left(\mathrm{h}_{\mathrm{t}}-\mathrm{h}\right)\left(\mathrm{h}_{\mathrm{t}}-\mathrm{h}\right)^{\prime}
$$

$\mathrm{T}$ is the sample size, $\mathrm{h} \_\mathrm{t}$ is a $\mathrm{N}^{*} 1$ vector of stock returns in period $\mathrm{t}$, and $\mathrm{h}$ is the average of return vectors. Then we get the inverse matrix of the covariance matrix, which is S2. To find out the optimal weight of the portfolio, we need to get four parameters A, B, C, D. A is the sum of all elements in the $S 2$ matrix. B is the sum of the product matrix (matrix $\mathrm{S} 2 \mathrm{R}$ ) of the $\mathrm{S} 2$ matrix and 
the matrix R. C is the sum product of the matrix $\mathrm{R}$ and matrix $\mathrm{S} 2 \mathrm{R}$. D equals $\mathrm{A}^{*} \mathrm{C}-\mathrm{B}^{\wedge} 2$.

Set a matrix $\mathrm{Z}, \mathrm{rf}$ is the monthly risk free rate.

$$
Z_{n}=\frac{R_{n}-\mathrm{rf}}{\mathrm{B}-\mathrm{A} * \mathrm{rf}}
$$

The optimal weight matrix $\mathrm{W}$ is:

$$
W=\mathrm{S} 2 * \mathrm{Z}
$$

After using the solver function in Excel, we get the weight and sharp ratio of this portfolio choice.

\section{RESULTS AND DISCUSSION}

Scalar variables and physical constants should be italicized, and a bold (non-italics) font should be used for vectors and matrices. Do not italicize subscripts unless they are variables. Equations should be either display (with a number in parentheses) or inline. Use the built-in Equation Editor or MathType to insert complex equations.

Display equations should be flush left and numbered consecutively, with equation numbers in parentheses and flush right. First, use the equation editor to create the equation. Then, select the equation, and set the "Equation" Style. Press the tab key and type the equation number in parentheses.

\subsection{Result of the quantitative analysis}

According to the result from the model, the optimization result of the portfolio is like the following table.

Table1. Weight of the three companies

\begin{tabular}{llll}
\hline & AMZN & DAL & WMT \\
\hline weight & 0.17181 & -0.09302 & 0.92120297 \\
\hline
\end{tabular}

The shape ratio is 2.271619 .

\subsection{Result of the qualitative analysis}

In this part, our team will conduct the fundamental analysis of the aviation industry, retail industry, and ecommerce industry during the Covid-19 period to support the result of the quantitative part.

Table2. Stock price of companies investigated

\begin{tabular}{ccll}
\hline \multicolumn{1}{c}{ Data } & \multicolumn{1}{c}{ Walmart } & \multicolumn{1}{c}{ Delta } & \multicolumn{1}{c}{ Amazon } \\
\hline $2020 / 1 / 1$ & 118.860001 & 58.93 & 1875 \\
$2020 / 2 / 1$ & 114.900002 & 56.200001 & 2010.59998 \\
$2020 / 3 / 1$ & 107.599998 & 46.220001 & 1906.48999 \\
$2020 / 4 / 1$ & 112.150002 & 26.59 & 1932.96997 \\
$2020 / 5 / 1$ & 121.480003 & 24.950001 & 2336.80005 \\
\hline
\end{tabular}

\begin{tabular}{llll}
\hline $2020 / 6 / 1$ & 123.440002 & 25.33 & 2448 \\
$2020 / 7 / 1$ & 119.449997 & 29.02 & 2757.98999 \\
$2020 / 8 / 1$ & 129.910004 & 24.85 & 3180.51001 \\
$2020 / 9 / 1$ & 141.199997 & 30.02 & 3489.58008 \\
$2020 / 10 / 1$ & 140.800003 & 30.99 & 3208 \\
$2020 / 11 / 1$ & 140.589996 & 30.620001 & 3061.73999 \\
$2020 / 12 / 1$ & 153.600006 & 40.790001 & 3188.5 \\
\hline
\end{tabular}

\subsubsection{Delta Airline (Aviation industry)}

The COVID-19 impact on world scheduled passenger traffic for the year 2020, compared to 2019 levels:

- Overall reduction of $50 \%$ of seats offered by airlines

- Overall reduction of 2,699 million passengers (-60\%)

- Approx. USD 371 billion loss of gross passenger operating revenues of airlines

The COVID-19 impact on world scheduled passenger traffic for the year 2021, compared to 2019 levels:

- Overall reduction of $33 \%$ to $39 \%$ of seats offered by airlines

- Overall reduction of 1,848 to 2,197 million passengers $(-41 \%$ to $-49 \%)$

- Approx. USD 278 to 327 billion loss of gross passenger operating revenues of airlines

Delta's passenger revenues declined $83 \%$ during the last quarter in 2020 as the airline dramatically cut its flight schedule, offering $63 \%$ fewer seats than the same period in 2019. Cargo operations were down by $25 \%$. The great economic loss on the aviation industry makes it a bad investment choice, corresponding to the portfolio choice.

\subsubsection{Walmart (Retail industry)}

The COVID-19 lockdown, the recession, and longterm changes in consumer behavior create unprecedented revenue challenges for traditional brickand-mortar retail. Some chains may be forced to seek bankruptcy protection. Many more will find that they can no longer support marginal stores. The hardest-hit segments will be department stores, apparel, and specialty retail.

Walmart adapts a set of strategies to overcome the difficulty of a pandemic.

Walmart provides many ways of selling, including online ordering, delivery, pick up at the curb, and instore shopping. Walmart provides essential goods that people still buy during the pandemic, like food and beverage and personal care, and nearly $55 \%$ to $60 \%$ of Walmart's business would normally be consumable. 
During the pandemic, a lot of government stimulus checks and unemployment assistance are spent at Walmart.

\subsubsection{Amazon (E-commerce industry)}

The COVID-19 lockdown, the recession, and longterm changes. The findings show the strong uptake of ecommerce across regions, with consumers in emerging economies making the greatest shift to online shopping. For example, Latin America's online marketplace Mercado Libre sold twice as many items per day in the second quarter of 2020 compared with the same period the previous year. And African e-commerce platform Jumia reported a $50 \%$ jump in transactions during the first six months of 2020. China's online share of retail sales rose from $19.4 \%$ to $24.6 \%$ between August 2019 and August 2020. In Kazakhstan, the online share of retail sales increased from $5 \%$ in 2019 to $9.4 \%$ in 2020 .

Thailand saw downloads of shopping apps jump $60 \%$ in just one week during March 2020. The trend towards e-commerce uptake seen in 2020 is likely to be sustained during recovery, the report says. But in many of the world's least developed countries, consumers and businesses haven't capitalized on pandemic-induced ecommerce opportunities due to persistent barriers.

These include costly broadband services, overreliance on cash, lack of consumers' trust, poor digital skills among the population, and governments' limited attention to e-commerce.

The uncertainty in COVID-19 changes people's shopping behavior and makes them purchase sanitizing products online, which improves the new users for ecommerce websites. Before the pandemic, Amazon represented around $4 \%$ of total U.S. retail sales. But with the new habits formed during the pandemic, UBS predicts that by 2025 , e-commerce will make up onequarter of total retail sales, up from $15 \%$. The firm also estimates that 100,000 brick-and-mortar retail outlets will close in the next five years. Consumers are increasingly shifting towards online shopping. Many of these shoppers may not get back to in-store shopping even after the pandemic.

\subsection{Correlation Matrix}

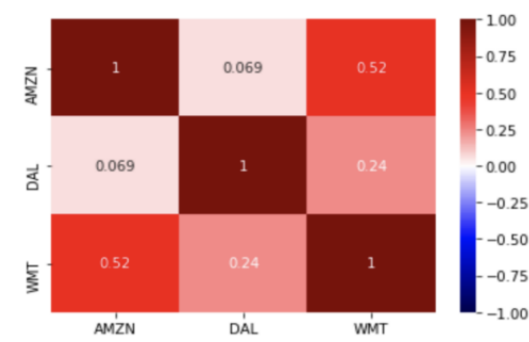

Figure 1 The correlation matrix of the three companies
The e-commerce industry and retail business have relatively high relevance, and the aviation industry has a low correlation with the other two industries.

Based on the data generated from the model, the largest investment should be put into Walmart, which is profitable with lower risk. Amazon is a company that performs well during the COVID-19 pandemic, but the price of the stock is too high comparing with that of Walmart. Delta Airline is the company you will not want to choose during the COIVD-19 because of its negative return on investment.

According to the estimation, in 2021, the aviation industry will recover gradually, but it is still not a good investment choice. Walmart is representative of the retail industry due to the increasing demand for shopping online. However, Walmart's success cannot cover the predicament of other middle size and small size businesses that declared bankruptcy during the pandemic. Amazon and the e-commerce industry flourish during the pandemic, and this trend will last for a long period.

\section{CONCLUSION}

This paper analyzes and suggests a value portfolio within the context of COVID-19. First of all, we adopted a diversified investment portfolio. Taking Delta Airline, Walmart, and Amazon as examples, we respectively adopted qualitative and quantitative methods for analysis and calculation. The study found that Walmart's stock was negatively affected by the outbreak. Amazon's stock, which benefited from people's demand for online shopping, rose sharply. Because of the lockdown of cities, Delta Airlines' stock fell. We suggest that firstly increasing the proportion of Amazon in the portfolio while reducing the weight of Walmart. Furthermore, buy more Delta Airlines when the price is low and wait for the industry to recover and grow up.

Based on the analysis results of the investment portfolio in this paper, the following investment methods with long-term value are summarized:

First of all, with the recovery of direct flights between China and the United States, the gradual improvement of the epidemic has brought recovery of the aviation industry. However, the current situation of the aviation industry is still far from satisfactory. Investors are advised to buy aviation stocks at a low price and wait for the industry to recover further and pick up. Secondly, with the increase of online shopping demand, the retail industry successfully used online shopping platforms to reverse the depression experienced in the early stage of the epidemic. It is suggested that investors should choose the retail industry as their main investment object. At the same time, the retail industry should vigorously develop the 
network platform to expand the online shopping business, and the existing online shopping business should be continuously updated and improved. Food, beverage, prescription drugs, personal-care products should become the critical development object of online shopping. Small retail and department stores should quickly transform into online shopping platforms to avoid bankruptcy. Finally, because e-commerce benefits from people's demand for online shopping in the epidemic, the industry has a good prospect. Therefore, e-commerce should become another primary investment object for investors. At the same time, it is suggested that developed countries should vigorously support and develop e-commerce while developing countries should reduce their dependence on cash and improve consumers' trust. The government should pay more attention to e-commerce and improve the existing ecommerce industry.

From the theoretical point of view, on the one hand, the research situation of the portfolio has a new academic expansion, which is discussing the theoretical value of the portfolio within the context of COVID-19; On the other hand, this paper proposes the basic idea of using Sharpe ratio to judge the stock portfolio as a new index reference for investors' investment.

\section{REFERENCES}

[1] Markowitz, Harry H. Portfolio Selection: Efficient Diversification of Investment. Journal of the Institute of Actuaries, 1992.

[2] Pastor L. Portfolio Selection and Asset Pricing Models[J]. The Journal of Finance, 2000, 55(1):179-223.

[3] Raymond, Kan, Guofu, et al. Optimal Portfolio Choice with Parameter Uncertainty[J]. The Journal of Financial and Quantitative Analysis, 2007.

[4] Konstantinos A, George M . Using Multiojective Algorithms to Solve the Discrete Mean-Variance Portfolio Selection[J]. International Journal of Economics \& Finance, 2010, 2(3):152-162.

[5] Wang J, Tu X S. The decision of the boundary of securities portfolio [J]. Forecasting, 1998(2).

[6] WANG Xiuguo, QIU Wanhua. A Smooth Newton Method for Inequality Constraint Optimization Problem [J].Operations Research and Management, 2004(05):65-69.

[7] Liu Mingming, Gao Yan. Optimal Portfolio Selection for Short Selling in Friction Markets [J]. Chinese Journal of Management Science, 2006, 14(5):23-27.

[8] Chen Guohua, Chen Shou, Fang Yong, et al. Portfolio selection model with fuzzy return rate
[J].Systems Engineering Theory \& Practice, 2009(07):8-15.

[9] Shi Yufeng, Zhang Shiying. Dynamic Portfolio Strategy Based on Time-varying Correlation Coefficient [J].Management Science, 2008, 21(005):105-110.

[10] Xie Xiaowen. Literature Review on Modern Portfolio Theory [J].Shopping Mall Modernization, 2010, 000(023):67-67.

[11] Deng HongHao. Review of the research literature on the risk measurement of Chinese stock market style portfolio based on Vine Copula method [J]. Financial Information, 2016, 000(019):83-84.

[12] Chen Xuerong, Zhang Yinqi, Zhou Wei. Portfolio Theory and Its Application in China's Securities Market [J].Systems Engineering, 2000(05):6-12.

[13] Lo Honglan, Wang Huachen. The New Development of Modern Portfolio Theory [J]. Journal of Systems Management, 2002, 11(003):185-189.

[14] Chen Jiawei. The theory of optimal bond portfolio and empirical analysis of China's bond funds [D].Shanghai Jiao Tong University.

[15] Zhang Sailan. The Application of Modern Securities Portfolio Theory in China's Securities Market [J].Time Finance, 2007(06):27-29.

[16] Deng Yanni. Financial Portfolio Theory and Empirical Analysis in China's Securities Market [J].Business Journal, 2020, 000(003):61,63.

[17] Liu Weifei, You Guiyun. The Application of Markowitz's Portfolio Theory in China's Securities Market [J].Economic Review, 2008(02):29-31.

[18] Gustafson, J. The role of portfolio theory in the development of securities markets $[\mathrm{J}]$.Shandong University, 2001

[19] Jia K. Analysis of the impact of COVID-19 on China's economy and countermeasures [J]. Economic Research Review, 2020(6):80-85.

[20] GUO C L. Impact of COVID-19 epidemic on overseas investment $[\mathrm{J}]$. International Finance, 2020, 467(05):40-45. (in Chinese)

[21] Yang Yuheng. Research on the Method of Large Scale Portfolio Selection Based on Chinese Stock Data [D].Xiamen University, 2018. 